When this analysis of minima is applied to the 25 pandemics, the results reveal an appreciable tendency for them to occur at solar minima, but only during the 18 th century. During the 19th and 20th centuries, the effect declines [15], which suggests that the relationship between solar activity and pandemics is more complex than Fig. 1 suggests. The decline may reflect secular changes in solar behavior, which are now known to occur despite much resistance to the idea by former generations of astronomers [16].

Increased occurrences of influenza pandemics at solar minima would be consistent with that reported from von Alvensleben in his critical letter [9]. The present results support $H \& W$ 's general claim of a relationship between sunspots and influenza, and suggest in addition that an allowance should be made for more complex and perhaps historically unstable patterns.

In summary, the sunspot-influenza hypothesis deserves heightened attention irrespective of whether H\&W's original idea of an invasion from space does or does not hold (see critique in [17]). According to epidemiologists, the number of deaths due to influenza pandemics in the present century is about as great as those due to the two World Wars combined, i.e., roughly 50 million. Influenza is "the only infectious disease among the top 10 killers in the United States" [4] "... it is an even greater threat to human lives in many parts of the Third World" ([5], p. 5). Furthermore, "the behaviour of influenza is so capricious that it is not possible to predict what it will do in the future ... With the enormous increase in the populations of the world ... it might be that pandemics will become more severe" ([18], p. 232). In view of the evidence furnished by the present study, the general resistance against relating influenza to sunspots might at least lose some of its irrational vigor.

Dr. A. von Alvensleben provided valuable information. Prof. F. Hoyle encouraged the present work by appropriate feedback. Dr. G. Dean suggested improvements to an earlier draft of this paper and simplified the method for calculating $Q$.

Received December 6, 1993 and April 11, 1994

1. Hoyle, F., Wickramasinghe, N. C.: Diseases from Space. London: Dent 1979; Hoyle, F., Wickramasinghe, N. C.: Living Comets. Cardiff: Univ. Cardiff College Press 1984; Hoyle, F., Wickramasinghe, N. C.: Nature 322, 509 (1986)

2. Verschuur, G. L., Kellermann, K. I. (eds.): Galactic and Extragalactic Radio Astronomy. Berlin: Springer 1988

3. Hoyle, F: The Intelligent Universe. A New View of Creation and Evolution. New York: Holt 1983

4. Patterson, K. D.: Pandemic Influenza 1700-1900. Totowa, N. J.: Rowman 1986

5. Fine, P., after Pyle, G. F.: The Diffusion of Influenza Patterns and Paradigms, p. 2. Totowa, N. J.: Rowman 1986

6. Hope-Simpson, R. E.: Nature 275, 86 (1978)

7. Beveridge, W. I. B.: Influenza, the Last Great Plague. London: Heinemann 1977

8. Hoyle, F., Wickramasinghe, N. C.: Nature 343, 304 (1990)

9. Alvensleben, A. von: ibid. 344, 374 (1990)

10. Creighton, C. A.: A History of Epidemics in Britain. Cambridge Univ. Press 1891, 1894, 2nd ed. London: Cass 1965
11. Alvensleben, A. von: (pers. comm.) He had obtained the data second hand, without being aware of selections by previous users

12. Assaad, F., Bektimirov, T., LjungarsEsteves, K., in: The Molekular Virology and Epidemiology of Influenza (C. H. Sheart-Harris, C. M. Potter, eds.). London: Academic Press 1984

13. Burnett, F. M.: Naturgeschichte der Infektionskrankheiten des Menschen. Frankfurt a.M.: Fischer 1971

14. Collier: Collier's Encyclopedia. CrowellCollier Educational Corporation 1970

15. Silverstein, A. M.: Pure Politics and Impure Science. The Swine Flu Affair. Baltimore: John Hopkins U. P. 1981

16. Tschijewsky, A.: Dtsch-Russ. Med. Z. 3 (1927)

17. Voigt, H. H. (Hrsg): Landolt-Börnstein. Bd. 1: Astronomie und Astrophysik. Berlin: Springer 1965; McKinnon, J. A.: Sunspot Numbers: 1610-1985 based on The Sunspot-Activity in the Years 1610-1960. Boulder, CO: World Data Center A for Solar-Terrestrial Physics 1987

18. Pfanzagl, J.: Z. theor. angew. Statist. 1, 130 (1953); Krüger, H.-P., Lienert, G. A.: Z. exp. angew. Psychol. 27, 460 (1980)

19. Ertel, S.: Z. Parapsychol. Grenzgeb. Psychol. 35, 178 (1993). This paper gives a more detailed account of the method. It also discusses some limitations and problems such as how genuine connections of dependent variables with solar minima may be distinguished from mere resonance covariation with solar minima, genuine maxima connections succeed the minima after 3 to 5 years and might give rise to misinterpretations.

20. Eddy, J. A.: Bull. Am. Astron. Soc. 7, 365 (1975)

21. Henderson, I. M., Hendy, M. D., Penny, D.: J. Theor. Biol. 140, 289 (1989)

22. Beveridge, W. I. B.: Hist. Phil. Life Sci. 13, 223 (1991)
Naturwissenschaften 81, 311-313 (1994) (c) Springer-Verlag 1994

\section{The Nature of the Chemical Bond in $\left(\mathrm{CH}_{3}\right)_{3} \mathrm{~N}-\mathrm{BCl}_{3}$ and $\left(\mathrm{CH}_{3}\right)_{3} \mathrm{~N}-\mathrm{AlCl}_{3}$}

\author{
V. Jonas and G. Frenking \\ Fachbereich Chemie der Universität, D-35032 Marburg
}

The nature of the chemical bond in donor-acceptor complexes remains a controversial issue $[1-3]$. The question is whether the donor-acceptor bond is mainly caused by covalent interactions, or if electrostatic forces are responsible for the bonding. We report about the bonding of the strongly bound donoracceptor complexes $\left(\mathrm{CH}_{3}\right)_{3} \mathrm{~N}-\mathrm{BCl}_{3}(\mathrm{l})$ and $\left(\mathrm{CH}_{3}\right)_{3} \mathrm{~N}-\mathrm{AlCl}_{3}$ (2). Although the molecules 1 and 2 are similar, the nature of the chemical bond is very different.
Figure 1 shows the calculated geometries at the MP2/TZ2P level of theory* of 1,2 , and the Lewis acids $\mathrm{BCl}_{3}$ and $\mathrm{AlCl}_{3}$. The experimental geometries are given in parentheses. The agreement between the theoretically predicted and experimen-

\footnotetext{
* The quantum chemical calculations have been done with the program system TURBOMOLE [4]. TZ2P for $\mathrm{B}, \mathrm{C}$, and $\mathrm{N}$ is a (9s5p2d)/[5s3p2d] basis set, TZ2P for $\mathrm{H}$ is a $(5 \mathrm{~s} 2 \mathrm{p}) /[3 \mathrm{~s} 2 \mathrm{p}]$ basis set from [5]. TZ2P for $\mathrm{Al}$ and $\mathrm{Cl}$ is a $(12 \mathrm{~s} 9 \mathrm{p} 2 \mathrm{~d}) /[6 \mathrm{~s} 5 \mathrm{p} 2 \mathrm{~d}]$ basis set from [6]. The $d$ polarization functions are from [7]. For further details of the calculations see [3].
} 


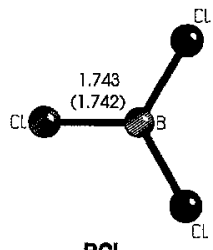

$\mathrm{BCl}_{3}$

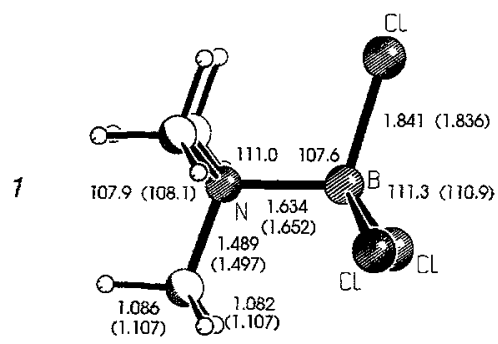

2

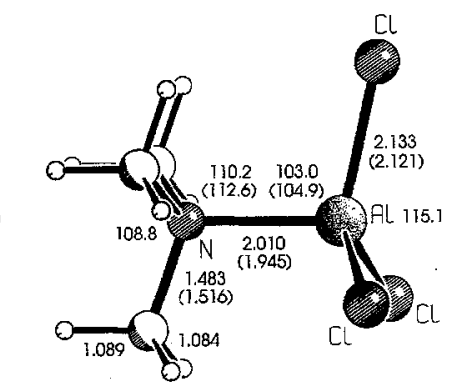

Fig. 1. Optimized geometries at MP2/TZ2P. Experimental gas phase values are given in parentheses (for $\mathrm{BCl}_{3}$ from [13], for $\mathrm{AlCl}_{3}$ from [14], for $\mathrm{Me}_{3} \mathrm{~N}-\mathrm{BCl}_{3}$ from [15], and for $\mathrm{Me}_{3} \mathrm{~N}-\mathrm{AlCl}_{3}$ from [16]). Bond distances in $\AA$, angles in degree

tally observed geometries is very good. The calculated N-Al bond length is longer than the experimental value determined by gas-phase electron diffraction [16]. However, it was noted in the experimental work [16] that the N-Al bond length is "considerably less accurate than the $\mathrm{N}-\mathrm{Al}$ bond distance determined by X-ray crystallography, 1.96(1) $\AA$ '. Because the donor-acceptor bond of a complex is always shorter in the solid state than in the gas phase [3], we believe that the reported value of 1.945 $\AA$ for the N-Al bond length of $2[16]$ is too short. Noteworthy is the considerable lengthening of the $\mathrm{B}-\mathrm{Cl}$ and $\mathrm{Al}-\mathrm{Cl}$ bonds upon formation of 1 and 2. This can be explained by the $\pi$ donation from the chlorine $p(\pi)$ orbitals into the formally empty $\mathrm{p}(\pi) \mathrm{AO}$ at boron and aluminium in the respective Lewis acids. The $p(\pi)$ donation is reduced in the complexes by the electron donation from the nitrogen lone-pair electrons, which forms the N-B and N-Al bond, respectively.
The $\mathrm{AlCl}_{3}$ complex 2 is the strongest donor-acceptor complex that is experimentally observed. The N-Al bond strength of 2 is $47.5 \pm 2.0 \mathrm{kcal} / \mathrm{mol}$ [8]. The calculated value at MP2/TZ2P is $49.3 \mathrm{kcal} / \mathrm{mol}$ [3]. The calculated bond energy of the $\mathrm{BCl}_{3}$ complex $l$ is 40.5 $\mathrm{kcal} / \mathrm{mol}$ [3]. There is no direct experimental value for the bond strength of 1 known to us. An estimate of $30.5 \mathrm{kcal} /$ mol has been made, but it is based on earlier experimental studies of other boron complexes, which are $\approx 10 \mathrm{kcal} /$ mol too low [9]. Therefore, we think that the theoretical value for the bond strength of $1(40.5 \mathrm{kcal} / \mathrm{mol})$ is probably correct. It follows that 1 and 2 are structurally similar complexes with strong donor-acceptor bonds.

In order to examine the nature of the donor-acceptor bonds in $I$ and 2 , we used the topological analysis of the electron density distribution developed by Bader and coworkers [10]. Figure 2 shows the counter line diagrams of the Laplacian distribution $\nabla^{2} \mathrm{e}(r)$ of 1 and 2 . The differences are striking. The nitrogen-boron bond of 1 is characterized by a large area of charge concentration $\left[\nabla^{2} \varrho(r)<0\right.$, solid lines], which is a strong indication of covalent bonding. This is supported by the calculated energy densities at the bond critical points $H_{\mathrm{b}}$. It has been found that covalent bonds have negative values of $H_{\mathrm{b}}$, with typical values between -1 and -3 Hartree/ $\AA^{3}$ [11]. Ionic bonds and van der Waals bonds, however, have $H_{\mathrm{b}}$ values $\geq 0$ [11]. The calculated value for the $\mathrm{N}$ $\mathrm{B}$ bond of 1 is -0.68 Hartree/ $\AA^{3}$, which indicates significant covalent contributions.

The Laplacian distribution of 2 in the $\mathrm{N}$ Al bonding region shows only a small deformation of the nitrogen lone-pair electrons towards the $\mathrm{Al}$ atom (Fig. 2). There is a large area of electron depletion $\left[\nabla^{2} \varrho(r)>0\right.$, dashed lines]. The energy density at the bond critical point $H_{\mathrm{b}}$ is only $-0.02 \mathrm{Hartree} / \AA^{3}$. It follows that the $\mathrm{N}-\mathrm{Al}$ bond of 2 is mainly caused by electrostatic interactions between the positive partial charge at $\mathrm{Al}$ and the negative charge at the nitrogen atom. Indeed, the calculated partial charge using the natural bond orbital partitioning scheme [12] at $\mathrm{Al}$ in $\mathrm{AlCl}_{3}$ is +1.51 , while it is only +0.32 at $\mathrm{B}$ in $\mathrm{BCl}_{3}[3]$. The negative charge at nitrogen in $\left(\mathrm{CH}_{3}\right)_{3} \mathrm{~N}$ is -0.51 .

In conclusion, we have shown that the

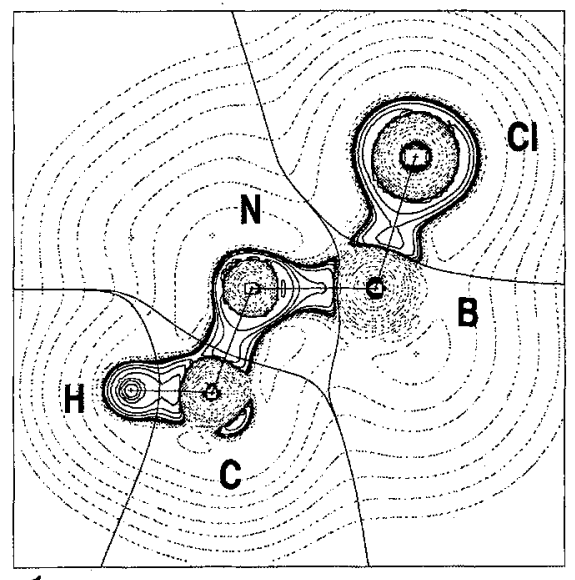

1

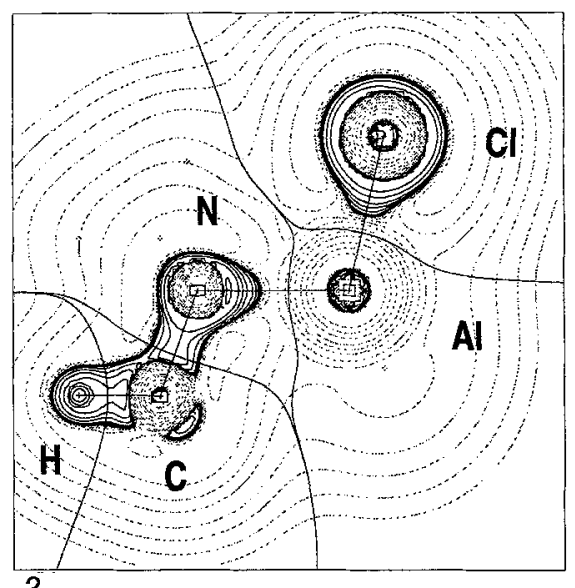

Fig. 2. Contour line diagrams of the Laplacian distribution $\nabla^{2} \mathrm{\varrho}(r)$ for 1 and 2. Dashed lines indicate charge depletion $\left[\nabla^{2} \mathrm{Q}(r)>0\right]$, solid lines indicate charge concentration $\left[\nabla^{2} \varrho(r)\right.$ $<0]$. The solid lines connecting the atomic nuclei are the bond paths, the solid lines separating the atomic nuclei indicate the zero-flux surfaces in the molecular plane. The bond critical point $r_{\mathrm{b}}$ is at the crossing of the bond path and the zero-flux surface

donor-acceptor bond in the strongest bound complex $\left(\mathrm{CH}_{3}\right)_{3} \mathrm{~N}-\mathrm{AlCl}_{3}$ has a mainly electrostatic character, while the bond of the similar complex $\left(\mathrm{CH}_{3}\right)_{3} \mathrm{~N}$ $\mathrm{BCl}_{3}$ has significant covalent contributions.

Received March 14, 1994

1. Umeyama, H., Morokuma, K.: J. Am. Chem. Soc. 98, 7208 (1976)

2. Røeggen, I.: Chem. Phys. 162, 271 (1992); Glendening, E. D., Streitwieser, A.: J. Chem. Phys. 100, 2900 (1994)

3. Jonas, V., Frenking, G., Reetz, M. T.: I. Am. Chem. Soc. (submitted)

4. Häser, M., Ahlrichs, R.: J. Comput. Chem. 10, 104 (1989); Haase, F., Ahlrichs, R.: ibid. 14, 907 (1993) 
5. Huzinaga, S.: Approximate Atomic Wavefunctions. Department of Chemistry Report, Univ. of Alberta, Edmonton, Alberta, Canada, 1971

6. McLean, A. D., Chandler, G. S.: J. Chem. Phys. 72, 5639 (1980)

7. Andzelm, J., Huzinaga, S., Klobukowski, M., Radzio, E., Sakai, Y., Tatewaki, H.: Gaussian Basis Sets For Molecular Calculations. Amsterdam: Elsevier 1984
8. Andersen, G. A., Forgaard, F. R., Haaland, A.: Acta Chem. Scand. 26, 1947 (1972)

9. McCoy, R. E., Bauer, S. H.: J. Am. Chem. Soc. 78, 2061 (1956)

10. Bader, R. F. W.: Acc. Chem. Res. 9, 18 (1985); Bader, R. F. W.: Atoms in Molecules. A Quantum Theory. New York: Oxford Univ. Press 1990

11. Cremer, D., Kraka, E.: Angew. Chem. 96, $612(1984)$
12. Reed, A. E., Curtiss, L. A., Weinhold, F. Chem. Rev. 88, 899 (1988)

13. Gershikov, A. G., Spiridonov, V. P., Zasorin, E. Z.: J. Mol. Struct. 99, 1 (1983)

14. Zasorin, E. Z., Rambidi, N. G.: Zh. Strukt. Khim. 8, 391 (1967)

15. Iijima, K., Shibata, S.: Bull. Chem. Soc Jpn. 53, 1908 (1980)

16. Almennigen, A., Haaland, A., Haugen, T., Novak, D. P.: Acta Chem. Scand. 27, 1821 (1973)
Naturwissenschaften 81, 313-316 (1994) (c) Springer-Verlag 1994

\section{Mandibular Gland Contents of a Colony of the Queenless Ponerine Ant Dinoponera australis}

\author{
N. J. Oldham, S. J. Keegans and E. D. Morgan \\ Department of Chemistry, Keele University, Staffordshire, ST5 5BG, England \\ R. V. S. Paiva and C. R. F. Brandão \\ Museu de Zoologia, Universidade de São Paulo, São Paulo 01064-979, Brazil \\ E. Schoeters and J. P. J. Billen \\ Zoologisch Instituut, Universiteit Leuven, B-3000 Leuven
}

True sociality in insects (eusociality) has been defined as simultaneous possession of three traits: individuals cooperate in caring for the young; there is a reproductive division of labor, with more or less sterile individuals working on behalf of fertile individuals in life stages capable of contributing to colony labor, so that offspring assist parents during some period of their life [1].

In many species of the ant subfamily Ponerinae, a morphologically distinct female (queen) is completely absent, raising the question of whether these species could still be called eusocial. However, in all cases studied, reproduction is taken over by one or relatively few fertilized workers, called "gamergates" [2], confirming that there is a division of reproductive labor. Moreover, recent studies indicate that most queenless ponerine species are monogynous (only one mated worker at a time) and that physical dominance plays an important role in establishing reproductive dominance [3]. Although the references bring indirect evidence that pheromones can also play a role in determining reproductive division of labor, in only one case
(Diacamma australe) mutilation of a gland inside the thoracic appendages (gemmae) of newly emerged workers by the gamergates precludes their production of sexual attractants [4].

The genus Dinoponera, containing the largest ants in the world, is restricted to continental South America, where its six accepted species [5] live in very small colonies [6] occupying ground nests in wet and dry forests. $D$. quadriceps, from the Brazilian Northeast, has one or a few gamergates and there is evidence that its reproductive system is sustained by dominance, resulting from aggressive interactions [7].

$D$. australis colonies are even smaller than those of $D$. quadriceps, with only one gamergate per colony (worker number $13 \pm 6, n=36$, data from a population living in a tropical dry forest in Itirapina, São Paulo, Brazil). They forage individually at daylight, stinging a variety of medium-sized arthropod prey [8]. Individually marked ants, living in artificial gypsum nests, showed a structure composed of a least two age groups: older foragers and younger nurses. The gamergate, although relatively old (may live up to 20 months), never leaves the nest chambers near the bottom of the nest and is constantly involved in aggressive interactions with nurses. This is particularly true after the emergence of callow nestmates (Paiva and Brandão, in preparation).

For the present paper two colonies of $D$. australis were collected at Itirapina in January 1990 and March 1991. They consisted respectively, of 13 workers, 5 eggs, 2 larvae and 10 pupae (Colony 1 ), and 14 workers and immatures (Colony 2). To determine the most common task performed by a given individual in Colony 2 , we labeled them all with numbered marks [9], glued on the pronotal disk with cyanoacrylate.

On completion of the behavioral observations, Colony 2 was sacrified. We determined relative age by the wear on the mandibles. The reproductive status was determined by the filling of spermathecae and by the stage of ovariole development. The colony had only one gamergate and the workers were divided into two groups, with three individuals acting as foragers, seven as nurses, and three with an unclear function. The glands were fixed for morphological studies (Billen et al., in preparation), with the exception of one mandibular gland from each individual, these were sealed individually in glass capillaries for GC-MS analysis, using the solventless technique in [10]. The low number of individuals composing each colony allowed us to study chemically, for the first time, all adult members of a society. Gas chromatography-mass spectrometry was carried out on a BP-1 fused silica capillary column of dimensions $12 \mathrm{~m} \times$ $0.2 \mathrm{~mm}$ with a $0.25 \mu \mathrm{m}$ film thickness (SGE Ltd.) in a Hewlett Packard 5890 gas chromatograph coupled to a $5970 \mathrm{~B}$ Mass Selective Detector. The glass capil- 